\title{
Microwave Assisted Green Synthesis of Ag/AgO Nanocatalyst as An Efficient OER Catalyst in Neutral Media
}

\section{Gokhan Elmaci}

Adiyaman University, Department of Chemistry, Adiyaman, Turkey

\section{A BS T RACT}

$\mathrm{T}$

he development of robust, stable and abundant materials that are operating under neutral conditions are of great importance for the electrocatalytic conversion of water to hydrogen using sunlight. Here, a robust and highly stable, silver oxide based electrocatalyst composite system for the efficient Oxygen Evolution Reaction (OER) was presented. The developed Ag/AgO composite catalyst with a small $(10-15 \mathrm{~nm})$ and homogenous particle size distribution was fabricated using microwave synthesis. In the neutral media, the $\mathrm{Ag} / \mathrm{AgO}$ electrocatalyst achieved $1 \mathrm{~mA} \mathrm{~cm}^{-2}$ current density at $600 \mathrm{mV}$ overpotential, and exhibited a lower Tafel slope of $80 \mathrm{mV} \mathrm{dec}^{-1}$ compared to $\mathrm{MnOx}$-based catalysts in the range of $450-600 \mathrm{mV}$. These values are comparable to those of the promising catalysts such as $\mathrm{Mn}, \mathrm{Co}, \mathrm{Ni}$ oxide based systems in the neutral media. The results showed that the developed electrocatalyst system based on $\mathrm{Ag} / \mathrm{AgO}$ composite could be used in multi-layer electrocatalyst system designs.

\section{Keywords:}

Silver nanoparticles; Microwave; Catalytic activity; Oxygen evolution reaction.
Article History:

Received: 2019/11/17

Accepted: 2019/12/17

Online: $2020 / 03 / 26$

Correspondence to: Gokhan Elmaci, Adıyaman University, Department of Chemistry, Faculty of Arts and Sciences, 02040, Adiyaman, Turkey E-Mail:gelmaci@adiyaman.edu.tr Phone: $+904162233800 / 3667$ Fax: +904162233809

\section{INTRODUCTION}

Tn the next 50 years, there is an urgent need for the sustainable and clean alternative energy sources to meet the increasing energy demands. Among the alternative energy sources, hydrogen energy is one of the most promising candidates [1-3]. Water, as an inexpensive and mostly abundant at around the world, is the main source for the generation of the hydrogen; however, obtaining hydrogen from water is thermodynamically unfavorable and requires a high amount of energy [4]. For this reason, economic energy conversion systems are required for the production of hydrogen gas from water [5].In this point, catalysts are considered as one of the most important parts of the energy transformation. Nevertheless, designing new sustainable catalysts, which can achieve energy conversions at low costs and improved in terms of shape, size and chemical composition, is a great criterion. Therefore, there has been a growing interest for the solution of this task [5-7].

In the last decades, nanomaterials have received much attention due to their unique physical, chemical, optical, magnetic, and electrical properties [8, 9]. Among these materials, precious metals such as Pd, Pt, $\mathrm{Au}$ and metal oxides; $\mathrm{Ru}_{2} \mathrm{O}$ and $\mathrm{Ir}_{2} \mathrm{O}$ are the inevitable part of the production of energy from water through its splitting to $\mathrm{H}_{2}$ and $\mathrm{O}_{2}[10,11]$.

However, their high costs and low abundances on the earth make handicap for their easy availability in the sustainable energy system $[12,13]$. Regarding these disadvantages, there have been a long-term demand for the development of robust, inexpensive and highly efficient electrocatalyst systems for the energy applications. In this perspective, earth-abundant metals such as $\mathrm{Ag}, \mathrm{Co}$, and $\mathrm{Ni}$ are considered as more economic alternatives [14, 15]. Nevertheless, a little attention has been devoted to the preparation of electrocatalyst from silver nanocomposites so far [16]. As well as the preparation of the silver nanocomposites, their stabilities in the media where they take a role in the energy applications are of great importance $[17,18]$. The nanocomposites may exhibit different characteristics owing to their unique structures and morphologies depending on their synthesis conditions [19]. Therefore, alternative approaches for the synthesis of silver nanocomposites are necessary and important as much as the application field where they take action.

In material synthesis, microwave technology (MT) is a promising alternative to the conventional methods depending on its superiority, especially in terms of spe- 
ed, low consumption of chemicals and energy [20]. MT not only keeps the reaction media steady state but also; therefore, promotes uniform product formation [20,21]. In this way, it also enhances the large-scale production of the advanced materials with the desired quality of interest. Recent studies showed that MT has also a significant role on the reaction kinetics, particle-size and morphology of the resulting products [22]. Due to these advantages, the MT has received an increasing attention in the synthesis of various materials such as metal oxides, carbon and precious metal based catalysts, peroxides and many mores [20-22]. In recent years, MT has also been facilitated in the fabrication of advanced materials, as well [23, 24].

Considering the above-mentioned advantages of MT, herein, we report the rapid, simple and highly reproducible synthesis of $\mathrm{Ag} / \mathrm{AgO}$ nanoparticles via microwave irradiation. The as synthesized nanoparticles were used as an efficient OER electrocatalyst for water splitting reactions. The prepared Ag/AgO nanocatalysts showed excellent water splitting activity under neutral media conditions.

\section{EXPERIMENTAL SECTION}

\section{Materials}

Silver nitrate $\left(\mathrm{AgNO}_{3}\right)$, oleic acid, oleylamine, ethanol and 1-octanol were purchased from Merck and used as receieved

\section{Synthesis of Ag/AgO nanoparticles}

In a typical procedure, a mixture of oleic acid $(40 \mathrm{ml} \mathrm{v} / \mathrm{v}$ 1/1), 1-octanol and oleylamine along with $100 \mathrm{mg} \mathrm{AgNO}$ was added into a $100 \mathrm{~mL}$ flask equipped with a stirring bar under nitrogen atmosphere. The as-prepared solution was refluxed under microwave irradiation according to the desired program $\left(100 \mathrm{~W}, 110{ }^{\circ} \mathrm{C}\right.$, hold for $10 \mathrm{~min}$ ) Subsequently, ethanol was added to the original reaction solution to precipitate $\mathrm{Ag} / \mathrm{AgO}$ NPs. Ag/AgO NPs was filtered, washed with deionized water several times, and then dried at $65^{\circ} \mathrm{C}$ for $24 \mathrm{~h}$.

\section{Instrumentation}

Powder X-ray diffraction patterns (XRD) of samples were collected using a Pan Analytical Empyrean instrument with $\mathrm{Cu} K \alpha$ radiation $(\lambda=1.54056 \AA)$ from 3 to $70^{\circ}(2 \theta)$ at a scanning rate of $2^{\circ} \mathrm{min}^{-1}$. The morphologies and structure of the samples were examined by scanning electron microscopy (SEM, ZEISS Sigma 300) and Transmission electron microscopy (TEM, Hitachi HT 7700). Microwave-irradiated reactions were carried out with a microwave reactor (Discover SP, CEM, Matthews, NC, USA). The electrochemical measurements were carried on Autolab workstation (PGSTAT204, Metrohm, Switzerland) using three-electrode system.

\section{Electrochemical measurements}

The electrocatalytic activitity of Ag NPs was tested in deoxygenated $0.2 \mathrm{M}$ phosphate (at $\mathrm{pH}$ 7) buffer solutions by using typical three electrode set-up similar to that reported by Joya et al. [16]. $\mathrm{Ag} / \mathrm{AgCl}$ electrode (sat. $\mathrm{KCl}$, $+204 \mathrm{mV}$ vs. $\mathrm{NHE}$ at $25^{\circ} \mathrm{C}$ ) was used as the reference and a Pt plate as the counter electrode $\left(1 \mathrm{~cm}^{2}\right)$. The potential, measured against an $\mathrm{Ag} / \mathrm{AgCl}$ electrode, was converted to the potential versus the reversible hydrogen electrode (RHE) according to $\left(\mathrm{E}_{\mathrm{RHE}}=\mathrm{E}_{\mathrm{Ag} / \mathrm{AgCl}}+0.204+0.059 \mathrm{pH}\right)$. The cyclic voltammogram (CV) and linear sweep voltammogram (LSV) were collected with a scan rate of 20 $\mathrm{mV} \cdot \mathrm{s}^{-1}$ between $0.2 \mathrm{~V}-1.3 \mathrm{~V}$ vs. $\mathrm{Ag} / \mathrm{AgCl}$. Tafel slope was calculated by using the following equation, $\eta=a+b \log (j)$, where $b$ is the Tafel slope, $J$ is the current density, $\eta$ is the overpotential value.

\section{Preparation of the electrode}

$\mathrm{Ag} / \mathrm{AgO}$ NPs were obtained in solid form by simple centrifugation from ethanol. A homogeneous suspension for electrode was prepared using the solid Ag/AgO NPs by thoroughly mixing $10 \mathrm{mg}$ of the catalyst with $10 \mu \mathrm{L}$ of 0.5 wt \% Nafion solution, $0.1 \mathrm{~mL}$ of isopropanol. The electrode was prepared by drop-coating $11 \mu \mathrm{L}$ of the prepared suspension onto a clean $1 \mathrm{~cm}^{2}$ Fluorine doped Tin Oxide (FTO). The coated electrode was then dried at $60^{\circ} \mathrm{C}$ in oven for $30 \mathrm{~min}$.

\section{RESULTS AND DISCUSSION}

\section{Characterization of $\mathrm{Ag} / \mathrm{AgO}$ thin film}

The surface of the Ag nanoparticles may be oxidized during the synthesis or film preparation steps (Fig. 1). This change was observed in the XRD results of Ag NPs composed of thin films. The cubic phase of Ag can be indexed to the peaks at $38.1^{\circ}, 44.3^{\circ}, 64.4^{\circ}$, and $77.5^{\circ}$ corresponding to (111), (200), (220), and (311) of Ag (JCPDS No. 04-0783)
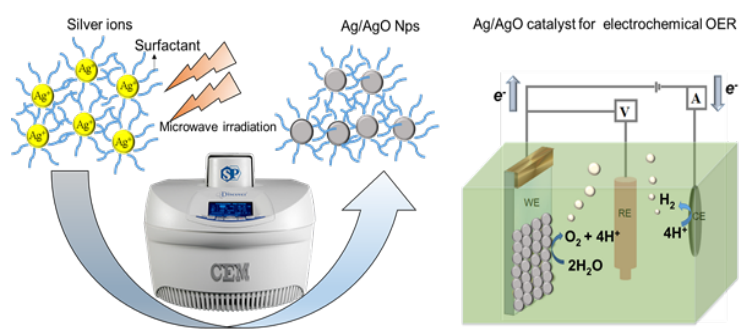

Figure 1. Schematic illustration of Ag/AgO NPs fabrication and its evolution as OER catalyst.. 


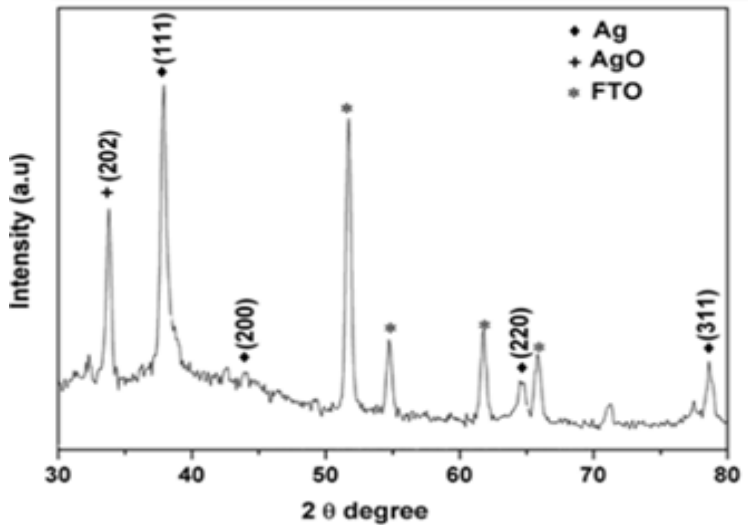

Figure 2. SX-ray diffraction (XRD) pattern for Ag NPs film on FTO glass.

[25], respectively. The peaks of $\mathrm{AgO}$ at $32.6^{\circ}$ is consistent with the (202) of the standard card of AgO (JCPDS No. 84-1108) [26].

The morphological study was performed using SEM analysis. Fig. 3 shows SEM images of Ag/AgO nanoparticles. SEM image of the electrode surface displays that the coated film consists of Ag-AgO NPs with homogeneous particle size. Film formation on FTO with $\mathrm{Ag} / \mathrm{AgO}$ catalyst was very smooth and homogeneous. This film preparation demonstrates that the applied procedure and method of application are suitable for the catalyst.

To further observe the morphology of $\mathrm{Ag} / \mathrm{AgO}$, the TEM analysis is showed in Fig 4. This image shows the spherical and plate-like morphologies of the NPs. The sizes of sphere-like particles were found to be in the range of 10 $15 \mathrm{~nm}$. Although the TEM analysis showed particle size of $10-15 \mathrm{~nm}$, the nanoparticles in the thin film examined by SEM analysis were about $100 \mathrm{~nm}$ in size. The difference in particle size in TEM and SEM analysis may be due to agglomeration of $\mathrm{Ag} / \mathrm{AgO}$ nanoparticles during film preparation.

\section{Water oxidation performance of $\mathrm{Ag} / \mathrm{AgO} \mathrm{NP}$ type electrocatalyst}

In recent years, in addition to metal oxides, plasmonic

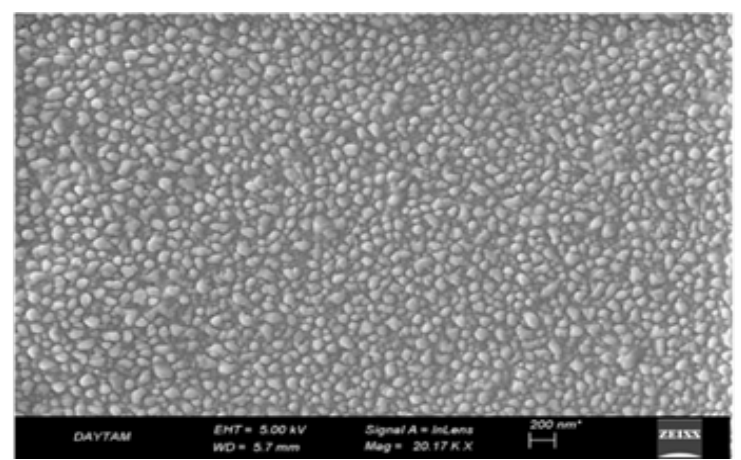

Figure 3. SEM image of Ag/AgO NPs film (top view).

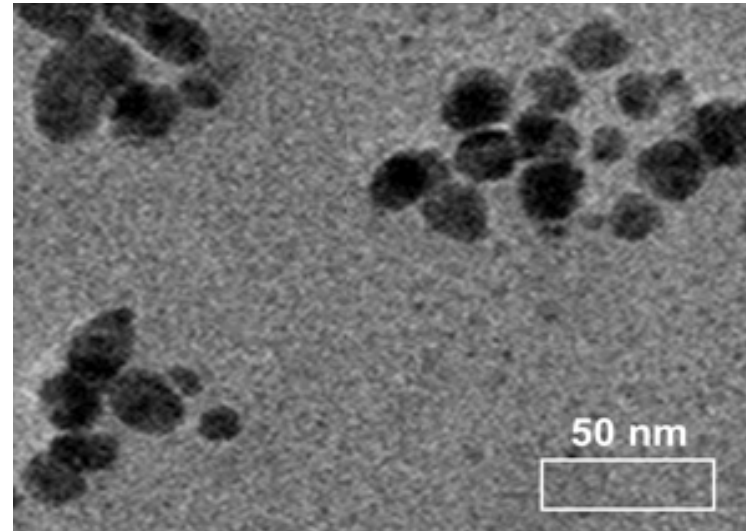

Figure 4. (TEM image of Ag/AgO NPs film.

nanostructures of noble metals (especially Ag and Au) have gained importance in the conversion of solar energy $[27,28]$. The particle size, shape and morphology of these nanoparticles can be observed in the SPR band [29]. These physical properties also affect their catalytic activity and stability [28]. Monitoring of physical parameters for the design of electrocatalysts and photocatalysts plays a vital role in the catalyst production process [30]. Therefore, we investigated the electrocatalytic activity of Ag/ AgO NPs, as "model"catalyst in water oxidation.

The synthesized Ag/AgO NPs was prepared as a film by $11 \mu \mathrm{L}$ drop-coating of homogeneous suspension onto FTO coated glass. Electrochemical water oxidation activity of Ag/AgO NPs electrodes was evaluated in deoxygenated $0.2 \mathrm{M}$ phosphate $(\mathrm{pH}=7)$ buffer solutions similar to that reported by Joya et al. [16]. Fig. 5a (CV) shows a sharp increase at $1.3 \mathrm{~V}$ (E vs NHE) $(\eta \approx 480 \mathrm{mV})$, associated with oxygen evolution from the electrode surface. In the neutral medium, $\mathrm{Ag} / \mathrm{AgO}$ electrocatalyst achieved $1 \mathrm{~mA} \mathrm{~cm}^{-2}$ current density at $600 \mathrm{mV}$ overpotential. At the same time, electrocatalyst exhibited a lower Tafel slope of $80 \mathrm{mV} \mathrm{dec}^{-1}$, compared to MnOx-based catalysts which have operating overpotential in the range of 450-600 mV [31] (Fig. 5a inset). These overpotential value and lower Tafel slope of the Ag/AgO based composite electrocatalyst are comparable to the promising catalyst canditates such as Mn, Co, Ni oxide based systems in neutral medium [32]. In addition, Ag electrocatalysts are quite stable at a neutral $\mathrm{pH}$ compared to the loss of activa-
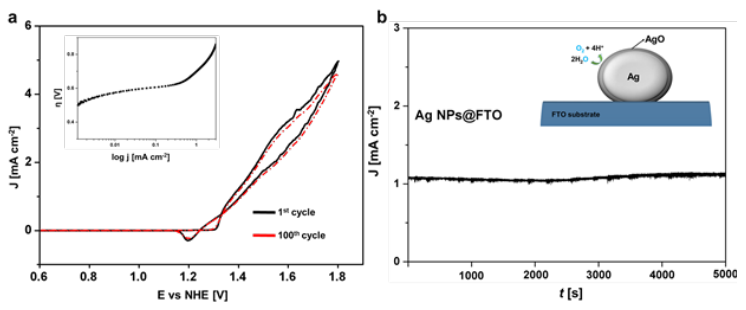

Figure 5. (a) Cyclic voltammetry (CV) (under a scanning rate of $20 \mathrm{mV}$ $\mathrm{s}-1$ ), (b) Long-term chronoamperometry (LC) (in deoxygenated 0.2 M phosphate buffer) at a constant potential of $1.40 \mathrm{~V}$ (E vs NHE). 
tion observed in Cyclic voltammetry and Long-term chronoamperometric measurements (Fig. 5a, 5b) in such oxide systems. As a result, electrocatalyst systems based on Ag/ AgO composite can be used in multi-layer electrocatalyst system designs.

\section{CONCLUSION}

In summary, $\mathrm{Ag} / \mathrm{AgO}$ based catalysts were prepared as homogenous spherical nanoparticles within 10 minutes using a microwave-assisted protocol. The as-synthesized $\mathrm{Ag} / \mathrm{AgO}$ nanocomposites were fully characterized by means of X-ray diffraction (XRD), Scanning electron microscopy (SEM), Transmission electron microscopy (TEM) methods and their electrocatalytic activities were evaluated for OER in the neutral media. The electrocatalytic activity exhibited by the $\mathrm{Ag} / \mathrm{AgO}$ composite was found to be comparable to the well-known metal oxidebased catalysts. This catalyst could be one of the promising catalysts in the energy conversion reactions.

\section{ACKNOWLEDGEMENT}

Author declares no conflicts of interest.

\section{References}

1. Owusu PA, Asumadu-Sarkodie, S. A. Review of renewable energy sources, sustainability issues and climate change mitigation. Cogent Engineering 3 (2016) 1167990.

2. de Vasconcelos BR, Lavoie JM. Recent advances in Power-to-X technology for the production of fuels and chemicals. Frontiers in Chemistry 7 (2019) 392.

3. Tuller HL. Solar to fuels conversion technologies: a perspective. Materials for Renewable and Sustainable Energy 6 (2017) 3.

4. Zeng K, Zhang, D. Recent progress in alkaline water electrolysis for hydrogen production and applications. Progress in Energy and Combustion Science 36 (2010) 307-326.

5. Kothari R, Buddhi D, Sawhney, R. Comparison of environmental and economic aspects of various hydrogen production methods. Renewable and Sustainable Energy Reviews 12 (2008) 553-563.

6. Leong G J, Schulze MC, Strand MB, Maloney D, Frisco S L, Dinh HN, Pivovar B, Richards RM, Shape-directed platinum nanoparticle synthesis: nanoscale design of novel catalysts. Applied Organometallic Chemistry 28 (2014) 1-17.

7. Lauritsen JV, Kibsgaard J, Helveg S, Topsøe H, Clausen BS, Lægsgaard E, Besenbacher F. Size-dependent structure of MoS2 nanocrystals. Nature Nanotechnology 2 (2007) 53-58.

8. Kim BH, Hackett MJ, Park J, Hyeon T. Synthesis, characterization, and application of ultrasmall nanoparticles. Chemistry of Materials 26 (2013) 59-71.

9. Ray PC. Size and shape dependent second order nonlinear optical properties of nanomaterials and their application in biological and chemical sensing. Chemical Reviews 110 (2010) 5332-5365.

10. Hu C, Zhang L, Gong J. Recent progress of mechanism comprehension and design of electrocatalysts for alkaline water splitting. Energy \& Environmental Science 12 (2019) 2620-2645.

11. Jafari T, Moharreri E, Amin AS, Miao R, Song W, Suib SL.
Photocatalytic water splitting the untamed dream: a review of recent advances. Molecules 21 (2016) 900.

12. Tachibana Y, Vayssieres L, Durrant JR. Artificial photosynthesis for solar water-splitting. Nature Photonics 6 (2012) 511-518.

13. Hisatomi T, Kubota J, Domen, K. Recent advances in semiconductors for photocatalytic and photoelectrochemical water splitting. Chemical Society Reviews 43 (2014) 7520-7535.

14. Li L, Shao Q, Huang X. Amorphous oxide nanostructures for advanced electrocatalysis. Chemistry A European Journal 25 (2019) $1-19$.

15. Hu J, Zhang C, Meng X, Lin H, Hu C, Long, X, Yang, S. Hydrogen evolution electrocatalysis with binary-nonmetal transition metal compounds. Journal of Materials Chemistry A 5 (2017) 5995-6012.

16. Joya KS, Ahmad Z, Joya YF, Garcia-Esparza AT, de Groot HJ. Efficient electrochemical water oxidation in neutral and nearneutral systems with a nanoscale silver-oxide catalyst. Nanoscale 8 (2016) 15033-15040.

17. Cozzoli PD, Comparelli R, Fanizza E, Curri ML, Agostiano A, Laub D. Photocatalytic synthesis of silver nanoparticles stabilized by $\mathrm{TiO} 2$ nanorods: A semiconductor/metal nanocomposite in homogeneous nonpolar solution. Journal of the American Chemical Society 126 (2004) 3868-3879.

18. Dallas P, Sharma VK, Zboril R. Silver polymeric nanocomposites as advanced antimicrobial agents: classification, synthetic paths, applications, and perspectives. Advances in Colloid and Interface Science 166 (2011) 119-135.

19. Camargo C, Satyanarayana KG, Wypych F. Nanocomposites: synthesis, structure, properties and new application opportunities. Materials Research 12 (2009) 1-39.

20. Clark DE, Sutton WH. Microwave processing of materials. Annual Review of Materials Science 26 (1996) 299-331.

21. Singh S, Gupta D, Jain V, Sharma AK. Microwave processing of materials and applications in manufacturing industries: a review. Materials and Manufacturing Processes 30 (2015) 1-29.

22. Thostenson E, Chou TW. Microwave processing: fundamentals and applications. Composites Part A: Applied Science and Manufacturing 30 (1999) 1055-1071.

23. Fan X, Guan J, Li Z, Mou F, Tong G, Wang W. One-pot low temperature solution synthesis, magnetic and microwave electromagnetic properties of single-crystal iron submicron cubes. Journal of Materials Chemistry 20 (2010) 1676-1682.

24. Cao JM, Feng J, Deng SG, Chang X, Wang J, Liu JS, Lu P, Lu HX, Zheng MB, Zhang F. Microwave-assisted solid-state synthesis of hydroxyapatite nanorods at room temperature. Journal of Materials Science 40 (2005) 6311-6313.

25. Han Y, Zheng J, Dong E. A novel nonenzymatic hydrogen peroxide sensor based on $\mathrm{Ag}-\mathrm{MnO} 2-\mathrm{MWCNTs}$ nanocomposites. Electrochimica Acta 90 (2013) 35-43.

26. Yang $\mathrm{H}$, Ren $\mathrm{Y}$, Wang $\mathrm{T}$, Wang C. Preparation and antibacterial activities of $\mathrm{Ag} / \mathrm{Ag}+/ \mathrm{Ag} 3+$ nanoparticle composites made by pomegranate (Punica granatum) rind extract. Results in physics 6 (2016) 299-304.

27. Osterloh F. Inorganic nanostructures for photoelectrochemical and photocatalytic water splitting. Chemical Society Reviews 42 (2013) 2294-2320.

28. Yi S, Zhang XB, Wulan BR, Yan JM, Jiang Q. Non-noble metals applied to solar water splitting. Energy \& Environmental Science 11 (2018) 3128-3156.

29. Jones MR, Osberg KD, Macfarlane RJ, Langille MR, Mirkin CA. Templated techniques for the synthesis and assembly of plasmonic nanostructures. Chemical Reviews 111 (2011) 3736-3827.

30. Seh ZW, Kibsgaard J, Dickens CF, Chorkendorff I, Norskov JK, 
Jaramillo TF. Combining theory and experiment in electrocatalysis: Insights into materials design. Science 355 (2017) eaad4998.

31. Melder J, Kwong WL, Shevela D, Messinger J, Kurz P. Electrocatalytic water oxidation by $\mathrm{MnOx} / \mathrm{C}$ : In situ catalyst formation, carbon substrate variations, and direct $\mathrm{O} 2 / \mathrm{CO} 2$ monitoring by membrane- inlet mass spectrometry. ChemSusChem 10 (2017) 4491-4502.

32. Lee SY, Gonzalez-Flores D, Ohms J, Trost T, Dau H, Zaharieva I, Kurz P. Screen-printed calcium-birnessite electrodes for water oxidation at neutral pH and an "Electrochemical Harriman series". ChemSusChem 7 (2014) 3442-3451. 